\title{
Broad and potent activity against SARS-like viruses by an engineered human monoclonal antibody
}

\author{
C. Garrett Rappazzo'*, Longping V. Tse ${ }^{2 *}$, Chengzi I. Kaku¹, Daniel Wrapp ${ }^{3}$, Mrunal Sakharkar', Deli Huang ${ }^{4}$, \\ Laura M. Deveau', Thomas J. Yockachonis ${ }^{5}$, Andrew S. Herbert ${ }^{6,7}$, Michael B. Battles ${ }^{1}$, Cecilia M. O'Brien ${ }^{6,7}$, \\ Michael E. Brown', James C. Geoghegan', Jonathan Belk', Linghang Peng ${ }^{4}$, Linlin Yang ${ }^{4}$, Yixuan Hou ${ }^{2}$, Trevor \\ D. Scobey ${ }^{2}$, Dennis R. Burton ${ }^{4,8,9,10}$, David Nemazee ${ }^{4}$, John M. Dye ${ }^{6}$, James E. Voss ${ }^{4}$, Bronwyn M. Gunn ${ }^{5}$, Jason S. \\ McLellan $^{3}$, Ralph S. Baric ${ }^{2,11} \uparrow$, Lisa E. Gralinski² ${ }^{2}$, Laura M. Walker ${ }^{1,12} \uparrow$
}

\begin{abstract}
${ }^{1}$ Adimab LLC, Lebanon, NH 03766, USA. '2Department of Epidemiology, The University of North Carolina at Chapel Hill, Chapel Hill, NC 27599, USA. ${ }^{3}$ Department of Molecular Biosciences, The University of Texas at Austin, Austin, TX 78712, USA. ${ }^{4}$ Department of Immunology and Microbiology, The Scripps Research Institute, La Jolla, CA

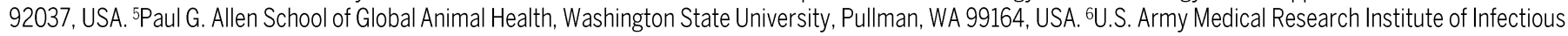
Diseases, Frederick, MD 21702, USA. ${ }^{7}$ The Geneva Foundation, 917 Pacific Avenue, Tacoma, WA 98402, USA. ${ }^{8}$ IAVI Neutralizing Antibody Center, The Scripps Research Institute, La Jolla, CA 92037, USA. ' Consortium for HIV/AIDS Vaccine Development (CHAVD), The Scripps Research Institute, La Jolla, CA 92037, USA. ${ }^{10}$ Ragon Institute of Massachusetts General Hospital, Massachusetts Institute of Technology, and Harvard, Cambridge, MA 02139, USA. ${ }^{11}$ Departments of Microbiology and Immunology, The University of North Carolina at Chapel Hill, Chapel Hill, NC 27599, USA. ${ }^{22}$ Adagio Therapeutics, Inc., Waltham, MA 02451, USA.
\end{abstract}

*These authors contributed equally to this work.

†Corresponding author. Email: rbaric@email.unc.edu (R.S.B.); Igralins@email.unc.edu (L.E.G.); laura.walker@adimab.com (L.M.W.)

The recurrent zoonotic spillover of coronaviruses (CoVs) into the human population underscores the need for broadly active countermeasures. We employed a directed evolution approach to engineer three SARSCoV-2 antibodies for enhanced neutralization breadth and potency. One of the affinity-matured variants, ADG-2, displays strong binding activity to a large panel of sarbecovirus receptor binding domains (RBDs) and neutralizes representative epidemic sarbecoviruses with high potency. Structural and biochemical studies demonstrate that ADG-2 employs a distinct angle of approach to recognize a highly conserved epitope overlapping the receptor binding site. In immunocompetent mouse models of SARS and COVID-19, prophylactic administration of ADG-2 provided complete protection against respiratory burden, viral replication in the lungs, and lung pathology. Altogether, ADG-2 represents a promising broad-spectrum therapeutic candidate against clade 1 sarbecoviruses.

The coronavirus disease 2019 (COVID-19) pandemic, caused by the $\beta$-coronavirus SARS-CoV-2, presents an urgent global health crisis. Although two vaccines and two monoclonal antibody (mAb) therapies have been authorized for emergency use by the FDA, it is unknown whether these vaccines and treatments will provide broad protection against new emerging SARS-CoV-2 strains that originate in humans or animal reservoirs (1). Furthermore, the recurrent zoonotic spillover of CoVs into the human population, along with the broad diversity of SARS-like CoVs circulating in animal reservoirs (2), suggests that new pathogenic CoVs are likely to emerge in the future and underscores the need for broadly active countermeasures.

Similar to other CoVs, the SARS-CoV-2 spike (S) protein mediates viral entry and is the only known target for neutralizing antibodies (nAbs). Although SARS-CoV and SARS-CoV2 share $76 \%$ amino acid identity in their S proteins, only a limited number of cross-neutralizing antibodies have been described to date (3-6). These rare broadly neutralizing antibodies (bnAbs) represent an attractive opportunity for therapeutic drug stockpiling to prevent or mitigate future outbreaks of SARS-related CoVs, but their limited neutralization potency may translate into suboptimal protective efficacy or impractical dosing regimens. Here, we show that such bnAbs can be engineered for improved neutralization potency while retaining neutralization breadth, and we demonstrate that these bnAbs can provide broad protection in vivo.

\section{Results \\ Affinity optimization of SARS-CoV-2 antibodies}

We isolated several antibodies from the memory B cells of a 2003 SARS survivor that cross-neutralize multiple SARSrelated viruses with relatively modest potency (3). Although breadth and potency are often opposing characteristics, we sought to engineer these bnAbs for improved neutralization potency against SARS-CoV-2 while also maintaining or improving neutralization breadth and potency against other SARS-like viruses. Because binding affinity and neutralization potency are generally well-correlated (7), we employed yeastsurface display technology to improve the binding affinities of three of the bnAbs (ADI-55688, ADI-55689, and ADI-56046) for a prefusion-stabilized SARS-CoV-2 S protein $(3,8-10)$. 
Yeast display libraries were generated by introducing diversity into the heavy (HC)- and light-chain (LC) variable genes of ADI-55688, ADI-55689, and ADI-56046 through oligonucleotide-based mutagenesis and transformation into Saccharomyces cerevisiae by homologous recombination (8). Following four rounds of selection with a recombinant SARSCoV-2 S1 protein, improved binding populations were sorted and between 20 and 50 unique clones from each lineage were screened for binding to SARS-CoV-2 S (10) (Fig. 1, A and B, and fig. S1). The highest affinity binders from each of the three lineages bound to the $\mathrm{S}$ protein with monovalent equilibrium dissociation constants $\left(\mathrm{K}_{\mathrm{D}} \mathrm{S}\right)$ in the picomolar range, representing 25 to 630 -fold improvements in binding relative to their respective parental clones and surpassing the affinities of several clinical-stage nAbs (S309, REGN10987, REGN10933, and CB6/LY-CoV16) (Fig. 1B and fig. S2A) (4, 11, 12). To determine whether the improvements in SARS-CoV-2 $\mathrm{S}$ binding affinity translated into enhanced neutralization potency, we selected between 9 and 14 affinity-matured progeny from each lineage and evaluated them for SARS-CoV-2 neutralizing activity in a murine leukemia virus (MLV) pseudovirus assay (13). All of the affinity-matured antibodies showed improved neutralizing activity relative to their parental clones, and the most potent neutralizers from each lineage (ADG-1, ADG-2, and ADG-3) displayed neutralization $\mathrm{IC}_{50} \mathrm{~S}$ that were comparable to or lower than those observed for the clinical SARS-CoV-2 nAb controls (Fig. 1B). Interestingly, however, we observed no correlation between the binding affinities and neutralization potencies of ADG-1, -2 , and -3 and the clinical-stage antibodies, suggesting neutralization potency is more tightly linked to fine epitope specificity than binding affinity to prefusion S (fig. S2B).

Because in vitro engineering can lead to polyreactivity with potential risks of off-target binding and accelerated clearance in vivo (14), we evaluated ADG-1, ADG-2, and ADG3 in a polyreactivity assay that is predictive of serum half-life in humans (15). All three antibodies lacked polyreactivity in this assay, indicating a low risk for poor pharmacokinetic behavior (fig. S3). The three antibodies also showed low hydrophobicity, a low propensity for self-interaction, and thermal stabilities within the range observed for clinically approved antibodies (fig. S3). Thus, the process of in vitro engineering appeared not to negatively impact biophysical properties that are often linked to characteristics such as serum half-life, ease of manufacturing, ability to formulate to high concentrations, and long-term stability.

\section{Neutralization breadth and potency of down-selected antibodies}

To determine whether the process of affinity engineering impacted neutralization breadth, we evaluated ADG-1, ADG-2, and ADG-3, as well as their respective parental antibodies, for neutralizing activity against a panel of representative clade 1 sarbecoviruses (SARS-CoV, SHC014-nLuc, SARS-CoV-2-nLuc, and WIV-1-nLuc). SHC014 and WIV-1 were selected because these two bat SARS-like viruses readily replicate in primary human airway cells, suggesting potential for direct transmission to humans $(16,17)$. Consistent with the MLV-SARS-CoV2 assay results, ADG-2 displayed highly potent neutralizing activity against authentic SARS-CoV-2-nLuc, with an $\mathrm{IC}_{50}$ comparable to or lower than those observed for clinical-stage SARS-CoV-2 nAbs $(4,11,12,18)$ (Fig. 1C and fig. S4). Furthermore, in contrast to the benchmark nAbs, ADG-2 displayed high neutralization potency against authentic SARS-CoV and the two bat SARS-related viruses, with $\mathrm{IC}_{50}$ s between 4 and 8 ng/mL (Fig. 1C and fig. S4). ADG-3 and the clinical nAb S309 also cross-neutralized all four sarbecoviruses but with markedly lower potency than ADG-2.

Based on its potent cross-neutralization and favorable biophysical properties, we selected ADG-2 as a lead therapeutic candidate and confirmed its potent neutralizing activity in an alternative authentic SARS-CoV-2 neutralization assay $\left(\mathrm{IC}_{50} \sim 1 \mathrm{ng} / \mathrm{mL}\right.$ ) (Fig. 1, C and D, and fig. S4). Because SARSCoV-2 D614G has emerged as the dominant pandemic strain (19), we also performed neutralization studies with MLVSARS-CoV-2 D614G and confirmed that ADG-2 retains potent neutralizing activity against this strain (fig. S5).

\section{ADG-2 displays broad binding activity to clade 1 sarbecovirus RBDs}

We further assessed the breadth of sarbecovirus recognition by ADG-2 by measuring its apparent binding affinity $\left(\mathrm{K}_{\mathrm{D}}{ }^{\mathrm{App}}\right)$ to a panel of 17 representative sarbecovirus RBDs expressed on the surface of yeast (20). Thirteen viruses were selected from clade 1-representing the closest known relatives of SARS-CoV-2 (GD-Pangolin and RaTG13) to the most divergent (SHC014 and Rs4231) - as well as four viruses from the distantly related clades 2 and 3 , which do not use ACE2 as a host receptor (21) (Fig. 2A). Recombinant hACE2-Fc and the benchmark SARS-CoV-2 nAbs described above were included as controls. In agreement with prior reports $(10,20)$, hACE2 only recognized clade 1 RBDs and bound with higher affinity to SARS-CoV-2 than SARS-CoV (Fig. 2B).

Consistent with their broadly neutralizing activities, S309, ADG-2, and ADG-3 displayed broad binding reactivity to clade 1 sarbecovirus RBDs, with ADG-2 and ADG-3 strongly binding 12/13 viruses and S309 binding all 13 (Fig. 2B). Notably, ADG-2 bound with high affinity ( $\mathrm{K}_{\mathrm{D}}{ }^{\mathrm{App}}$ 0.24-1.12 nM) to every clade 1 sarbecovirus RBD that exhibited detectable hACE2 binding, supporting the high degree of ADG-2 epitope conservation among sarbecoviruses that can use hACE2 as a receptor. In contrast, ADG-1 only bound to 9/13 viruses and CB6/LY-CoV16, LY-CoV555, REGN10987, and REGN10933 bound only the closest evolutionary neighbor(s) of SARS- 
CoV-2, consistent with their narrow neutralization profiles (Figs. 2B and $1 \mathrm{C}$ ).

Prior studies have shown that RBD mutants that are resistant to commonly elicited SARS-CoV-2 nAbs are circulating in the human population $(19,22-24)$. We therefore sought to assess the breadth of ADG-2 binding to naturally circulating SARS-CoV-2 variants that contain single amino acid substitutions in the RBD. ADG-1, ADG-3, and the benchmark SARS-CoV-2 nAbs were included as comparators. Using the yeast surface-display platform, we expressed the 30 most frequently observed SARS-CoV-2 RBD variants reported in the GISAID database as well as six naturally circulating SARS-CoV-2 variants reported to be resistant to certain SARS-CoV-2 nAbs $(19,22,25)$. One or more of the 36 SARS-CoV-2 variants exhibited loss of binding to ADG-1, CB6/LY-CoV16, LY-CoV555, REGN10987, and REGN10933, as defined by $>75 \%$ loss relative to the WT construct (Fig. 2C). Notably, the loss-of-binding variants identified for REGN10987 and REGN10933 partially overlapped with those identified in previous in vitro neutralization escape studies, validating the use of RBD display for the prediction of antibody escape mutations (26). In contrast, ADG-2, ADG-3, and S309 bound to all 36 variants at levels $\geq 50 \%$ of WT SARSCoV-2 (Fig. 2C). This result, combined with the remarkable neutralization breadth observed for these three mAbs (Figs. $1 \mathrm{C}$ and 2, B and D), indicates a potential link between epitope conservation and resistance to viral escape. Finally, all of the antibodies retained high affinity binding to the N501Y variant, which is the only RBD mutation present in the rapidly spreading B.1.1.7 lineage (27), suggesting that this new emerging SARS-CoV-2 strain is likely susceptible to neutralization by these antibodies.

\section{ADG-2 binds to a conserved neutralizing epitope overlapping the hACE2 binding site}

To gain further insight into the antigenic surface recognized by ADG-2, we generated a mutagenized yeast surface-display RBD library and performed rounds of selection to identify $\mathrm{RBD}$ variants that exhibited loss of binding to ADG-2 relative to the WT construct (Fig. 3A and fig. S6, A and B). To exclude mutations that globally disrupt the conformation of the RBD, a final round of positive selection was performed using a mixture of recombinant hACE2-Fc and two RBD-directed mAbs (S309 and CR3022) that target non-overlapping epitopes distinct from the ADG-2 binding site $(4,28)$ (figs. S6B and S7). Selected RBD mutants were individually tested for binding to ADG-2, recombinant hACE2-Fc, CR3022, and S309 to confirm site-specific knock-down mutations (fig. S6C). Substitutions at only four RBD positions specifically abrogated ADG-2 binding: D405E, G502E/R/V, G504A/D/R/S/V and $\mathrm{Y} 505 \mathrm{C} / \mathrm{N} / \mathrm{S}$ (Fig. 3B). These four residues are highly conserved among the clade 1 sarbecovirus subgenus and invariant among SARS-CoV-1, SARS-CoV-2, SHC014 and WIV1 viruses (Fig. 3C), providing a molecular explanation for the breadth of binding and neutralization exhibited by ADG2. Consistent with the conservation of these residues among clade 1 sarbecoviruses, none of the substitutions that impacted ADG-2 binding were present in full-length SARS-CoV2 sequences deposited in the GISAID database at a frequency greater than $0.001 \%$ as of December 9, 2020. In addition, 3 of the 4 identified mutations that abrogate ADG-2 binding lie within the hACE2 binding site (29) and at least one mutation at each position (G502E/R/V, G504V and $\mathrm{Y} 505 \mathrm{C} / \mathrm{N} / \mathrm{S}$ ) also abrogated hACE2 binding (Fig. 3B), likely accounting for their absence among circulating SARS-CoV-2 isolates. These results suggest that the evolutionary conservation of the ADG-2 epitope is likely directly linked to ACE2 binding.

To support the results of this experiment, we performed low-resolution cryogenic electron microscopy (cryo-EM) of the complex of ADG-2 bound to prefusion-stabilized SARS-CoV-2 S. This yielded a $\sim 6 \AA$ resolution 3D reconstruction that clearly had at least one ADG-2 Fab bound to an RBD in the up conformation and allowed us to dock in previously determined high-resolution models of the SARS-CoV-2 spike and a homologous Fab (Fig. 3D; fig. S8, A to D; and table S1). Consistent with our fine epitope mapping experiments (Fig. 3B and fig. S7C), the epitope recognized by ADG-2 overlaps the hACE2-binding site and each position identified by epitope mapping clustered to the cleft between the heavy and light chains of ADG-2 (Fig. 3D). This epitope also partially overlaps with those recognized by frequently observed 'class 1' SARS-CoV-2 nAbs (30) (Fig. 3E). However, in contrast to previously reported nAbs in this class, ADG-2 binds with a divergent angle of approach and displays broadly neutralizing activity (30) (Figs. 3E and $1 \mathrm{C}$ and fig. S8E). Thus, ADG-2 binds to a highly conserved motif through a distinct angle of approach.

\section{ADG-2 potently triggers Fc-mediated effector functions in vitro}

Because Fc-mediated effector functions can contribute to protection independently of viral neutralization, we assessed the ability of ADG-2 to induce antibody-dependent natural killer cell activation and degranulation (ADNKDA), antibodydependent cellular phagocytosis (ADCP) mediated by monocytes and neutrophils, and antibody-mediated complement deposition (ADCD) using in vitro effector function assays (31). Benchmark SARS-CoV-2 nAbs S309 and REGN10987 were included as comparators. Interestingly, while ADG-2, S309, and REGN10987 showed comparable recruitment of phagocytosis (Fig. 4B), these antibodies differed with respect to complement deposition and NK cell activation (Fig. 4, A and C); S309 showed reduced complement deposition compared with ADG-2 and REGN10987, and ADG-2 showed 
superior NK cell activation over both S309 and REGN10987 (Fig. 4). In summary, ADG-2 robustly triggers diverse Fcmediated effector activities with potencies comparable or superior to those of current SARS-CoV-2 clinical antibodies.

\section{ADG-2 broadly protects in murine models of SARS and COVID-19}

Finally, we tested the ability of ADG-2 to provide broad in vivo protection in immunocompetent mouse models of SARS and COVID-19 using mouse-adapted SARS-CoV (MA15) and SARS-CoV-2 (MA10), respectively $(32,33)$. Balb/c mice were prophylactically treated with either $200 \mu \mathrm{g}$ of ADG-2 or PBS via IP injection 12 hours prior to intranasal challenge with a $10^{3} \mathrm{PFU}$ dose of MA15 or MA10. All mice were monitored daily for weight loss and changes in respiratory function, and groups of mice were euthanized at day two or four post-infection to allow for measurement of virus replication in the lung and analysis of lung histopathology. We observed substantial, progressive weight loss in sham-treated mice infected with both viruses along with increases in Penh, a calculated measure of airway resistance (33). In contrast, mice treated prophylactically with ADG-2 demonstrated minimal weight loss, no change in Penh and no signs of gross pathology at the time of harvest (Fig. 5, A and B). Furthermore, prophylactic antibody treatment prevented viral replication in the lungs at both two- and four-days post-infection (dpi). We next investigated the ability of ADG-2 to act anti-virally against SARSCoV-2 MA10 in a therapeutic setting. Mice were treated with $200 \mu \mathrm{g}$ of ADG-2 or PBS 12 hours following intranasal challenge with a $10^{3} \mathrm{PFU}$ dose of MA10. Mice given therapeutic ADG-2 had intermediate levels of weight loss, moderate respiratory function changes and some gross lung pathology; significantly more than prophylactically treated mice but significantly less than sham-treated mice (Fig. 5C). Therapeutic antibody treatment also resulted in a significant reduction in lung viral loads at four dpi, but not at two dpi, relative to sham-treated mice. We conclude that ADG-2 treatment can reduce disease burden in mice infected with both SARS-CoV MA15 and SARS-CoV-2 MA10.

\section{Discussion}

Since the beginning of the COVID-19 pandemic, a plethora of potently neutralizing SARS-CoV-2 antibodies have been isolated and some have rapidly advanced into clinical trials (34). However, the epitopes recognized by most of these nAbs are highly variable among other clade 1 sarbecoviruses, hence limiting their neutralization breadth and increasing their susceptibility to antibody escape mutations (22). Here, we described an engineered antibody that neutralizes SARS-CoV-2 with a potency that rivals current lead SARS-CoV-2 clinical nAbs, but also broadly neutralizes other clade 1 sarbecoviruses, potently triggers Fc-mediated effector functions, and provides significant protection against SARS and COVID19 disease in mouse models. Thus, ADG-2 represents a promising candidate for the prevention and treatment of not only COVID-19, but also future respiratory diseases caused by preemergent SARS-related CoVs. Furthermore, our fine epitope mapping and structural studies demonstrate that ADG-2 employs a distinct angle of approach to recognize a highly conserved epitope overlapping the receptor binding site. This epitope represents an Achilles' heel for clade 1 sarbecoviruses and hence is an attractive target for the rational design of "pan-SARS" vaccines that aim to elicit similar broadly protective antibodies.

\section{REFERENCES AND NOTES}

1. B. B. Oude Munnink, R. S. Sikkema, D. F. Nieuwenhuijse, R. J. Molenaar, E. Munger, R. Molenkamp, A. van der Spek, P. Tolsma, A. Rietveld, M. Brouwer, N. Bouwmeester-Vincken, F. Harders, R. Hakze-van der Honing, M. C. A. WegdamBlans, R. J. Bouwstra, C. GeurtsvanKessel, A. A. van der Eijk, F. C. Velkers, L. A. M. Smit, A. Stegeman, W. H. M. van der Poel, M. P. G. Koopmans, Transmission of SARS-CoV-2 on mink farms between humans and mink and back to humans. Science 371, 172-177 (2021). doi:10.1126/science. abe5901 Medline

2. J. Cui, F. Li, Z. L. Shi, Origin and evolution of pathogenic coronaviruses. Nat. Rev. Microbiol. 17, 181-192 (2019). doi:10.1038/s41579-018-0118-9 Medline

3. A. Z. Wec, D. Wrapp, A. S. Herbert, D. P. Maurer, D. Haslwanter, M. Sakharkar, R. K. Jangra, M. E. Dieterle, A. Lilov, D. Huang, L. V. Tse, N. V. Johnson, C.-L. Hsieh, N. Wang, J. H. Nett, E. Champney, I. Burnina, M. Brown, S. Lin, M. Sinclair, C. Johnson, S. Pudi, R. Bortz 3rd, A. S. Wirchnianski, E. Laudermilch, C. Florez, J. M. Fels, C. M. O'Brien, B. S. Graham, D. Nemazee, D. R. Burton, R. S. Baric, J. E. Voss, K. Chandran, J. M. Dye, J. S. McLellan, L. M. Walker, Broad neutralization of SARSrelated viruses by human monoclonal antibodies. Science 369, 731-736 (2020). doi:10.1126/science. abc7424 Medline

4. D. Pinto, Y.-J. Park, M. Beltramello, A. C. Walls, M. A. Tortorici, S. Bianchi, S. Jaconi, K. Culap, F. Zatta, A. De Marco, A. Peter, B. Guarino, R. Spreafico, E. Cameroni, J. B. Case, R. E. Chen, C. Havenar-Daughton, G. Snell, A. Telenti, H. W. Virgin, A. Lanzavecchia, M. S. Diamond, K. Fink, D. Veesler, D. Corti, Cross-neutralization of SARS-CoV-2 by a human monoclonal SARS-CoV antibody. Nature 583, 290-295 (2020). doi:10.1038/s41586-020-2349-y Medline

5. C. Wang, W. Li, D. Drabek, N. M. A. Okba, R. van Haperen, A. D. M. E. Osterhaus, F. J. M. van Kuppeveld, B. L. Haagmans, F. Grosveld, B.-J. Bosch, A human monoclonal antibody blocking SARS-CoV-2 infection. Nat. Commun. 11, 2251 (2020). doi:10.1038/s41467-020-16256-y Medline

6. H. Liu, N. C. Wu, M. Yuan, S. Bangaru, J. L. Torres, T. G. Caniels, J. van Schooten, X. Zhu, C. D. Lee, P. J. M. Brouwer, M. J. van Gils, R. W. Sanders, A. B. Ward, I. A. Wilson, Cross-Neutralization of a SARS-CoV-2 Antibody to a Functionally Conserved Site Is Mediated by Avidity. Immunity 53, 1272-1280.e5 (2020). doi:10.1016/i.immuni.2020.10.023 Medline

7. P. W. Parren, D. R. Burton, The antiviral activity of antibodies in vitro and in vivo. Adv. Immunol. 77, 195-262 (2001).do:10.1016/S0065-2776(01)77018-6Medline

8. A. Z. Wec, Z. A. Bornholdt, S. He, A. S. Herbert, E. Goodwin, A. S. Wirchnianski, B. M. Gunn, Z. Zhang, W. Zhu, G. Liu, D. M. Abelson, C. L. Moyer, R. K. Jangra, R. M. James, R. R. Bakken, N. Bohorova, O. Bohorov, D. H. Kim, M. H. Pauly, J. Velasco, R. H. Bortz 3rd, K. J. Whaley, T. Goldstein, S. J. Anthony, G. Alter, L. M. Walker, J. M. Dye, L. Zeitlin, X. Qiu, K. Chandran, Development of a Human Antibody Cocktail that Deploys Multiple Functions to Confer Pan-Ebolavirus Protection. Cell Host Microbe 25, 39-48.e5 (2019). doi:10.1016/i.chom.2018.12.004 Medline

9. M. J. Feldhaus, R. W. Siegel, L. K. Opresko, J. R. Coleman, J. M. W. Feldhaus, Y. A. Yeung, J. R. Cochran, P. Heinzelman, D. Colby, J. Swers, C. Graff, H. S. Wiley, K. D. Wittrup. Flow-cytometric isolation of human antibodies from a nonimmune Saccharomyces cerevisiae surface display library. Nat. Biotechnol. 21, 163-170 (2003). doi:10.1038/nbt785 Medline

10. D. Wrapp, N. Wang, K. S. Corbett, J. A. Goldsmith, C.-L. Hsieh, O. Abiona, B. S. Graham, J. S McLellan, Cryo-EM structure of the 2019-nCoV spike in the prefusion conformation. Science 367, 1260-1263 (2020). doi:10.1126/science abb2507 Medline 
11. J. Hansen, A. Baum, K. E. Pascal, V. Russo, S. Giordano, E. Wloga, B. O. Fulton, Y. Yan, K. Koon, K. Patel, K. M. Chung, A. Hermann, E. Ullman, J. Cruz, A. Rafique, T. Huang, J. Fairhurst, C. Libertiny, M. Malbec, W. Y. Lee, R. Welsh, G. Farr, S. Pennington, D. Deshpande, J. Cheng, A. Watty, P. Bouffard, R. Babb, N. Levenkova, C. Chen, B. Zhang, A. Romero Hernandez, K. Saotome, Y. Zhou, M. Franklin, S. Sivapalasingam, D. C. Lye, S. Weston, J. Logue, R. Haupt, M. Frieman, G. Chen, W. Olson, A. J. Murphy, N. Stahl, G. D. Yancopoulos, C. A. Kyratsous, Studies in humanized mice and convalescent humans yield a SARS-CoV-2 antibody cocktail. Science 369, 1010-1014 (2020). doi:10.1126/science.abd0827 Medline

12. R. Shi, C. Shan, X. Duan, Z. Chen, P. Liu, J. Song, T. Song, X. Bi, C. Han, L. Wu, G. Gao, X. Hu, Y. Zhang, Z. Tong, W. Huang, W. J. Liu, G. Wu, B. Zhang, L. Wang, J. Qi, H. Feng, F.-S. Wang, Q. Wang, G. F. Gao, Z. Yuan, J. Yan, A human neutralizing antibody targets the receptor-binding site of SARS-CoV-2. Nature 584, 120-124 (2020). doi:10.1038/s41586-020-2381-y Medline

13. T. Giroglou, J. Cinatl Jr., H. Rabenau, C. Drosten, H. Schwalbe, H. W. Doerr, D. von Laer, Retroviral vectors pseudotyped with severe acute respiratory syndrome coronavirus S protein. J. Virol. 78, 9007-9015 (2004). doi:10.1128/JVI.78.17.9007-9015.2004 Medline

14. S. A. Sievers, L. Scharf, A. P. West Jr., P. J. Bjorkman, Antibody engineering for increased potency, breadth and half-life. Curr. Opin. HIV AIDS 10, 151-159 (2015). doi:10.1097/COH.0000000000000148 Medline

15. L. Shehata, D. P. Maurer, A. Z. Wec, A. Lilov, E. Champney, T. Sun, K. Archambault, I. Burnina, H. Lynaugh, X. Zhi, Y. Xu, L. M. Walker, Affinity Maturation Enhances Antibody Specificity but Compromises Conformational Stability. Cell Rep. 28, 3300-3308.e4 (2019). doi:10.1016/j.celrep.2019.08.056 Medline

16. V. D. Menachery, B. L. Yount Jr., A. C. Sims, K. Debbink, S. S. Agnihothram, L. E. Gralinski, R. L. Graham, T. Scobey, J. A. Plante, S. R. Royal, J. Swanstrom, T. P. Sheahan, R. J. Pickles, D. Corti, S. H. Randell, A. Lanzavecchia, W. A. Marasco, R. S. Baric, SARS-like WIV1-CoV poised for human emergence. Proc. Natl. Acad. Sci. U.S.A. 113, 3048-3053 (2016). doi:10.1073/pnas.1517719113 Medline

17. V. D. Menachery, B. L. Yount Jr., K. Debbink, S. Agnihothram, L. E. Gralinski, J. A. Plante, R. L. Graham, T. Scobey, X.-Y. Ge, E. F. Donaldson, S. H. Randell, A. Lanzavecchia, W. A. Marasco, Z.-L. Shi, R. S. Baric, A SARS-like cluster of circulating bat coronaviruses shows potential for human emergence. Nat. Med. 21, 1508-1513 (2015). doi:10.1038/nm.3985 Medline

18. B. E. Jones et al., LY-CoV555, a rapidly isolated potent neutralizing antibody, provides protection in a non-human primate model of SARS-CoV-2 infection. bioRxiv (2020); https://doi.org/10.1101/2020.09.30.318972.

19. B. Korber, W. M. Fischer, S. Gnanakaran, H. Yoon, J. Theiler, W. Abfalterer, N. Hengartner, E. E. Giorgi, T. Bhattacharya, B. Foley, K. M. Hastie, M. D. Parker, D. G. Partridge, C. M. Evans, T. M. Freeman, T. I. de Silva, C. McDanal, L. G. Perez, H. Tang, A. Moon-Walker, S. P. Whelan, C. C. LaBranche, E. O. Saphire, D. C. Montefiori; Sheffield COVID-19 Genomics Group, Tracking Changes in SARS-CoV2 Spike: Evidence that D614G Increases Infectivity of the COVID-19 Virus. Cell 182, 812-827.e19 (2020). doi:10.1016/j.cell.2020.06.043 Medline

20. T. N. Starr, A. J. Greaney, S. K. Hilton, D. Ellis, K. H. D. Crawford, A. S. Dingens, M. J. Navarro, J. E. Bowen, M. A. Tortorici, A. C. Walls, N. P. King, D. Veesler, J. D. Bloom, Deep Mutational Scanning of SARS-CoV-2 Receptor Binding Domain Reveals Constraints on Folding and ACE2 Binding. Cell 182, 1295-1310.e20 (2020). doi:10.1016/i.cell.2020.08.012 Medline

21. M. Letko, A. Marzi, V. Munster, Functional assessment of cell entry and receptor usage for SARS-CoV-2 and other lineage B betacoronaviruses. Nat. Microbiol. 5 , 562-569 (2020). doi:10.1038/s41564-020-0688-y Medline

22. D. F. Robbiani, C. Gaebler, F. Muecksch, J. C. C. Lorenzi, Z. Wang, A. Cho, M. Agudelo, C. O. Barnes, A. Gazumyan, S. Finkin, T. Hägglöf, T. Y. Oliveira, C. Viant, A. Hurley, H.-H. Hoffmann, K. G. Millard, R. G. Kost, M. Cipolla, K. Gordon, F. Bianchini, S. T. Chen, V. Ramos, R. Patel, J. Dizon, I. Shimeliovich, P. Mendoza, H. Hartweger, L. Nogueira, M. Pack, J. Horowitz, F. Schmidt, Y. Weisblum, E. Michailidis, A. W. Ashbrook, E. Waltari, J. E. Pak, K. E. Huey-Tubman, N. Koranda, P. R. Hoffman, A. P. West Jr., C. M. Rice, T. Hatziioannou, P. J. Bjorkman, P. D. Bieniasz, M. Caskey, M. C. Nussenzweig, Convergent antibody responses to SARS-CoV-2 in convalescent individuals. Nature 584, 437-442 (2020). doi:10.1038/s41586-020-2456-9 Medline

23. Y. Weisblum, F. Schmidt, F. Zhang, J. DaSilva, D. Poston, J. C. C. Lorenzi,
F. Muecksch, M. Rutkowska, H.-H. Hoffmann, E. Michailidis, C. Gaebler, M. Agudelo, A. Cho, Z. Wang, A. Gazumyan, M. Cipolla, L. Luchsinger, C. D. Hillyer, M. Caskey, D. F. Robbiani, C. M. Rice, M. C. Nussenzweig, T. Hatziioannou, P. D. Bieniasz, Escape from neutralizing antibodies by SARS-CoV-2 spike protein variants. elife 9, e61312 (2020). doi:10.7554/elife.61312 Medline

24. A. J. Greaney, T. N. Starr, P. Gilchuk, S. J. Zost, E. Binshtein, A. N. Loes, S. K. Hilton, J. Huddleston, R. Eguia, K. H. D. Crawford, A. S. Dingens, R. S. Nargi, R. E. Sutton, N. Suryadevara, P. W. Rothlauf, Z. Liu, S. P. J. Whelan, R. H. Carnahan, J. E. Crowe Jr., J. D. Bloom, Complete Mapping of Mutations to the SARS-CoV-2 Spike Receptor-Binding Domain that Escape Antibody Recognition. Cell Host Microbe 29, 44-57.e9 (2021). doi:10.1016/j.chom.2020.11.007 Medline

25. Y. Shu, J. McCauley, GISAID: Global initiative on sharing all influenza data - from vision to reality. Euro Surveill. 22, 30494 (2017). doi:10.2807/15607917.ES.2017.22.13.30494 Medline

26. A. Baum, B. O. Fulton, E. Wloga, R. Copin, K. E. Pascal, V. Russo, S. Giordano, K. Lanza, N. Negron, M. Ni, Y. Wei, G. S. Atwal, A. J. Murphy, N. Stahl, G. D. Yancopoulos, C. A. Kyratsous, Antibody cocktail to SARS-CoV-2 spike protein prevents rapid mutational escape seen with individual antibodies. Science 369 , 1014-1018 (2020). doi:10.1126/science.abd0831 Medline

27. K. Leung, M. H. Shum, G. M. Leung, T. T. Lam, J. T. Wu, Early empirical assessment of the N501Y mutant strains of SARS-CoV-2 in the United Kingdom, October to November 2020. medRxiv, 2020.2012.2020.20248581 (2020); https://doi.org/10.1101/2020.12.20.20248581

28. M. Yuan, N. C. Wu, X. Zhu, C. D. Lee, R. T. Y. So, H. Lv, C. K. P. Mok, I. A. Wilson, A highly conserved cryptic epitope in the receptor binding domains of SARS-CoV-2 and SARS-CoV. Science 368, 630-633 (2020). doi:10.1126/science.abb7269 Medline

29. J. Lan, J. Ge, J. Yu, S. Shan, H. Zhou, S. Fan, Q. Zhang, X. Shi, Q. Wang, L. Zhang, $X$. Wang, Structure of the SARS-CoV-2 spike receptor-binding domain bound to the ACE2 receptor. Nature 581, 215-220 (2020). doi:10.1038/s41586-020-2180-5 Medline

30. C. O. Barnes, C. A. Jette, M. E. Abernathy, K. A. Dam, S. R. Esswein, H. B. Gristick, A. G. Malyutin, N. G. Sharaf, K. E. Huey-Tubman, Y. E. Lee, D. F. Robbiani, M. C. Nussenzweig, A. P. West Jr., P. J. Bjorkman, SARS-CoV-2 neutralizing antibody structures inform therapeutic strategies. Nature 588, 682-687 (2020). doi:10.1038/s41586-020-2852-1 Medline

31. B. M. Gunn, W.-H. Yu, M. M. Karim, J. M. Brannan, A. S. Herbert, A. Z. Wec, P. J. Halfmann, M. L. Fusco, S. L. Schendel, K. Gangavarapu, T. Krause, X. Qiu, S. He, J. Das, T. J. Suscovich, J. Lai, K. Chandran, L. Zeitlin, J. E. Crowe Jr., D. Lauffenburger, Y. Kawaoka, G. P. Kobinger, K. G. Andersen, J. M. Dye, E. O. Saphire, G. Alter, A Role for Fc Function in Therapeutic Monoclonal AntibodyMediated Protection against Ebola Virus. Cell Host Microbe 24, 221-233.e5 (2018). doi:10.1016/i.chom.2018.07.009 Medline

32. A. Roberts, D. Deming, C. D. Paddock, A. Cheng, B. Yount, L. Vogel, B. D. Herman, T. Sheahan, M. Heise, G. L. Genrich, S. R. Zaki, R. Baric, K. Subbarao, A mouseadapted SARS-coronavirus causes disease and mortality in BALB/c mice. PLOS Pathog. 3, e5 (2007). doi:10.1371/journal.ppat.0030005 Medline

33. S. R. Leist, K. H. Dinnon 3rd, A. Schäfer, L. V. Tse, K. Okuda, Y. J. Hou, A. West, C. E. Edwards, W. Sanders, E. J. Fritch, K. L. Gully, T. Scobey, A. J. Brown, T. P. Sheahan, N. J. Moorman, R. C. Boucher, L. E. Gralinski, S. A. Montgomery, R. S. Baric, A Mouse-Adapted SARS-CoV-2 Induces Acute Lung Injury and Mortality in Standard Laboratory Mice. Cell 183, 1070-1085.e12 (2020). doi:10.1016/i.cell.2020.09.050 Medline

34. A. Renn, Y. Fu, X. Hu, M. D. Hall, A. Simeonov, Fruitful Neutralizing Antibody Pipeline Brings Hope To Defeat SARS-Cov-2. Trends Pharmacol. Sci. 41, 815-829 (2020). doi:10.1016/j,tips.2020.07.004 Medline

35. M. Sarzotti-Kelsoe, R. T. Bailer, E. Turk, C. L. Lin, M. Bilska, K. M. Greene, H. Gao, C. A. Todd, D. A. Ozaki, M. S. Seaman, J. R. Mascola, D. C. Montefiori, Optimization and validation of the TZM-bl assay for standardized assessments of neutralizing antibodies against HIV-1. J. Immunol. Methods 409, 131-146 (2014). doi:10.1016/i.im.2013.11.022 Medline

36. Y. J. Hou, K. Okuda, C. E. Edwards, D. R. Martinez, T. Asakura, K. H. Dinnon 3rd, T. Kato, R. E. Lee, B. L. Yount, T. M. Mascenik, G. Chen, K. N. Olivier, A. Ghio, L. V. Tse, S. R. Leist, L. E. Gralinski, A. Schäfer, H. Dang, R. Gilmore, S. Nakano, L. Sun, M. L. Fulcher, A. Livraghi-Butrico, N. I. Nicely, M. Cameron, C. Cameron, D. J. Kelvin, A. 
de Silva, D. M. Margolis, A. Markmann, L. Bartelt, R. Zumwalt, F. J. Martinez, S. P. Salvatore, A. Borczuk, P. R. Tata, V. Sontake, A. Kimple, I. Jaspers, W. K. O'Neal, S. H. Randell, R. C. Boucher, R. S. Baric, SARS-CoV-2 Reverse Genetics Reveals a Variable Infection Gradient in the Respiratory Tract. Cell 182, 429-446.e14 (2020). doi:10.1016/i.cell.2020.05.042 Medline

37. T. F. Rogers, F. Zhao, D. Huang, N. Beutler, A. Burns, W. T. He, O. Limbo, C. Smith, G. Song, J. Woehl, L. Yang, R. K. Abbott, S. Callaghan, E. Garcia, J. Hurtado, M. Parren, L. Peng, S. Ramirez, J. Ricketts, M. J. Ricciardi, S. A. Rawlings, N. C. Wu, M. Yuan, D. M. Smith, D. Nemazee, J. R. Teijaro, J. E. Voss, I. A. Wilson, R. Andrabi, B. Briney, E. Landais, D. Sok, J. G. Jardine, D. R. Burton, Isolation of potent SARSCoV-2 neutralizing antibodies and protection from disease in a small animal model. Science 369, 956-963 (2020). doi:10.1126/science. abc7520 Medline

38. Y. Xu, W. Roach, T. Sun, T. Jain, B. Prinz, T.-Y. Yu, J. Torrey, J. Thomas, P. Bobrowicz, M. Vásquez, K. D. Wittrup, E. Krauland, Addressing polyspecificity of antibodies selected from an in vitro yeast presentation system: A FACS-based, high-throughput selection and analytical tool. Protein Eng. Des. Sel. 26, 663-670 (2013). doi:10.1093/protein/gzt047Medline

39. T. Jain, T. Sun, S. Durand, A. Hall, N. R. Houston, J. H. Nett, B. Sharkey, B. Bobrowicz, I. Caffry, Y. Yu, Y. Cao, H. Lynaugh, M. Brown, H. Baruah, L. T. Gray, E. M. Krauland, Y. Xu, M. Vásquez, K. D. Wittrup, Biophysical properties of the clinical-stage antibody landscape. Proc. Natl. Acad. Sci. U.S.A. 114, 944-949 (2017). doi:10.1073/pnas.1616408114 Medline

40. Y. Liu, I. Caffry, J. Wu, S. B. Geng, T. Jain, T. Sun, F. Reid, Y. Cao, P. Estep, Y. Yu, M. Vásquez, P. M. Tessier, Y. Xu, High-throughput screening for developability during early-stage antibody discovery using self-interaction nanoparticle spectroscopy. mAbs 6, 483-492 (2014). doi:10.4161/mabs.27431 Medline

41. F. He, C. E. Woods, G. W. Becker, L. O. Narhi, V. I. Razinkov, High-throughput assessment of thermal and colloidal stability parameters for monoclonal antibody formulations.J.Pharm. Sci. 100, 5126-5141(2011).doi:10.1002/ips.22712 Medline

42. P. Estep, I. Caffry, Y. Yu, T. Sun, Y. Cao, H. Lynaugh, T. Jain, M. Vásquez, P. M. Tessier, Y. Xu, An alternative assay to hydrophobic interaction chromatography for high-throughput characterization of monoclonal antibodies. mAbs 7, 553-561 (2015). doi:10.1080/19420862.2015.1016694 Medline

43. C. D. Livingstone, G. J. Barton, Protein sequence alignments: A strategy for the hierarchical analysis of residue conservation. Comput. Appl. Biosci. 9, 745-756 (1993). doi:10.1093/bioinformatics/9.6.745 Medline

44. B. Carragher, N. Kisseberth, D. Kriegman, R. A. Milligan, C. S. Potter, J. Pulokas, A. Reilein, Leginon: An automated system for acquisition of images from vitreous ice specimens.J.Struct.Biol.132,33-45(2000).doi:10.1006/jsbi.2000.4314 Medline

45. D. Tegunov, P. Cramer, Real-time cryo-electron microscopy data preprocessing with Warp. Nat. Methods 16, 1146-1152 (2019). doi:10.1038/s41592-019-0580-y Medline

46. A. Punjani, J. L. Rubinstein, D. J. Fleet, M. A. Brubaker, cryoSPARC: Algorithms for rapid unsupervised cryo-EM structure determination. Nat. Methods 14, 290-296 (2017). doi:10.1038/nmeth.4169 Medline

47. A. Punjani, H. Zhang, D. J. Fleet, Non-uniform refinement: Adaptive regularization improves single-particle cryo-EM reconstruction. Nat. Methods 17, 1214-1221 (2020). doi:10.1038/s41592-020-00990-8 Medline

48. E. Goodwin, M. S. A. Gilman, D. Wrapp, M. Chen, J. O. Ngwuta, S. M. Moin, P. Bai, A. Sivasubramanian, R. I. Connor, P. F. Wright, B. S. Graham, J. S. McLellan, L. M. Walker, Infants Infected with Respiratory Syncytial Virus Generate Potent Neutralizing Antibodies that Lack Somatic Hypermutation. Immunity 48, 339349.e5 (2018). doi:10.1016/j.immuni.2018.01.005 Medline

49. E. F. Pettersen, T. D. Goddard, C. C. Huang, G. S. Couch, D. M. Greenblatt, E. C. Meng, T. E. Ferrin, UCSF Chimera-A visualization system for exploratory research and analysis. J. Comput. Chem. 25, 1605-1612 (2004). doi:10.1002/icc. 20084 Medline

50. L. E. Gralinski, T. P. Sheahan, T. E. Morrison, V. D. Menachery, K. Jensen, S. R. Leist, A. Whitmore, M. T. Heise, R. S. Baric, Complement Activation Contributes to Severe Acute Respiratory Syndrome Coronavirus Pathogenesis. mBio 9, e0175318 (2018). doi:10.1128/mBio.01753-18 Medline

\section{ACKNOWLEDGMENTS}

We thank T. Boland for assistance with SARS-CoV-2 sequence analysis and C. Williams for assistance with figure preparation. We thank E. Krauland, J. Nett, and M. Vasquez for helpful comments on the manuscript. We thank J. Ludes-
Meyers for assistance with cell transfection. All IgGs were sequenced by Adimab's Molecular Core and produced by the High Throughput Expression group. BLI binding experiments were performed by Adimab's Protein Analytics group. Opinions, conclusions, interpretations, and recommendations are those of the authors and are not necessarily endorsed by the U.S. Army. The mention of trade names or commercial products does not constitute endorsement or recommendation for use by the Department of the Army or the Department of Defense. Funding: This work was funded in part by National Institutes of Health (NIH)/National Institute of Allergy and Infectious Diseases (NIAID) grants awarded to J.S.M. (R01-Al12751), D.N. (R01-Al132317 and R01-Al073148), and R.S.B. (R01-Al132178 and U54 CA260543). J.E.V. was also supported by the Bill and Melinda Gates Foundation (OPP 1183956). B.M.G. and J.M.D. were supported by NIH/NIAID grant 5U19AI142777. Author contributions: L.M.W., L.E.G. and R.S.B. conceived and designed the study. L.M.D. and J.B. performed the directed evolution experiments. L.V.T., D.H., A.S.H., C.M.O., L.P., L.Y., T.D.S., D.R.B., D.N., J.M.D., J.V. and R.S.B. developed, designed, and performed neutralization assays. M.E.B. and J.C.G. designed and supervised developability and biolayer interferometry assays. C.G.R., C.I.K., M.S., and M.B.B. designed and performed the yeast surface-display RBD experiments. D.W. and J.S.M. designed and performed Biacore SPR and structural assays. T.J.Y. and B.M.G. designed and performed Fc-effector functional assays. L.E.G. designed and performed the animal challenge studies. C.G.R., L.V.T., C.I.K., D.W., M.S., D.H., L.M.D., A.S.H., M.B.B., B.M.G., L.E.G., and L.M.W. analyzed the data. C.G.R., L.V.T., C.I.K., D.W., M.S., D.H., B.M.G., L.E.G., and L.M.W. wrote the manuscript and all authors reviewed and edited the paper. Competing interests:C.G.R., C.I.K., M.S., L.M.D., M.B.B., M.E.B., J.C.G., and L.M.W. are employees of Adimab, LLC and may hold shares in Adimab, LLC. L.M.W. is an employee of Adagio Therapeutics Inc. and holds shares in Adagio Therapeutics Inc. D.R.B. is on the SAB of Adimab, LLC and Adagio Therapeutics Inc. and holds shares in Adimab, LLC. L.M.W. and J.B. are inventors on a patent application submitted by Adagio Therapeutics, Inc. describing the engineered SARS-CoV-2 antibodies. Data and material availability: Antibody sequences have been deposited in GenBank under accession codes MW417369-MW417400. The ADG-2 cryo-EM density map has been deposited into the Electron Microscopy Data Bank under the accession code EMD-23160. All other data are available in the manuscript or supporting material. IgGs are available from the corresponding author under MTA from Adagio Therapeutics, Inc. The MA15 (SARS-CoV) challenge virus is available from BEI as NR-44006, the MA10 (SARS-CoV-2) virus has been deposited but is not yet shipping while they confirm the sequence. MA10 is available from UNC using standard MTA agreements as we wait for BEI to be ready for orders. The hACE2 cell lines and constructs for pseudoviruses and proteins are available from D.N. under an MTA with Scripps. We gratefully acknowledge the authors from the originating laboratories and the submitting laboratories, who generated and shared via GISAID genetic sequence data on which

this research is based (table S2). This work is licensed under a Creative Commons Attribution 4.0 International (CC BY 4.0) license, which permits unrestricted use, distribution, and reproduction in any medium, provided the original work is properly cited. To view a copy of this license, visit https://creativecommons.org/licenses/by/4.0/. This license does not apply to figures/photos/artwork or other content included in the article that is credited to a third party; obtain authorization from the rights holder before using such material.

\section{SUPPLEMENTARY MATERIALS}

\section{science. sciencemag.org/cgi/content/full/science.abf4830/DC1}

Materials and Methods

Figs. S1 to S8

Tables S1 and S2

References (35-50)

MDAR Reproducibility Checklist

30 October 2020; accepted 19 January 2021

Published online 25 January 2021

10.1126/science.abf4830 
A
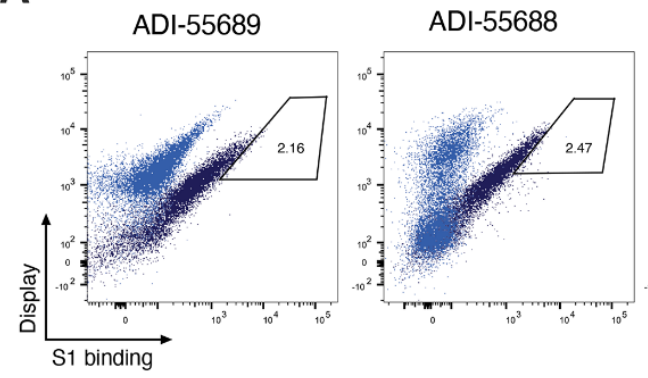

ADI-56046

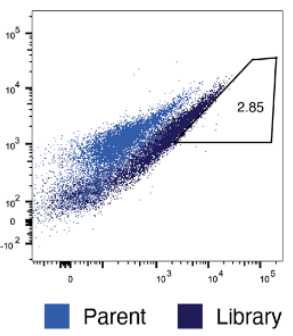

B

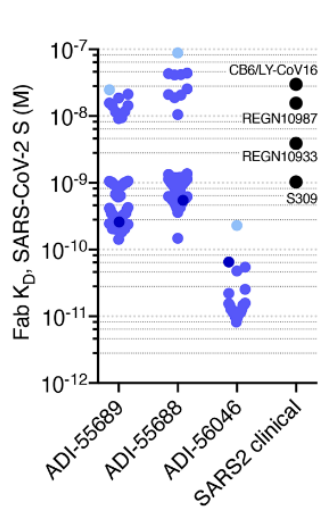

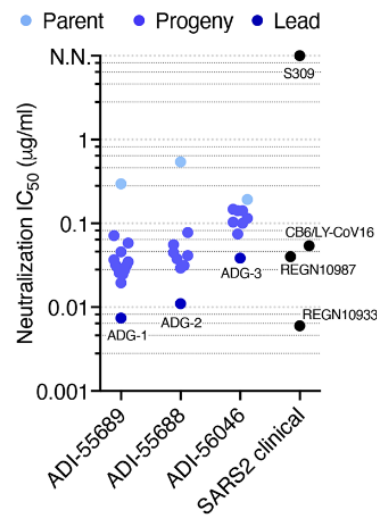

C

\begin{tabular}{|c|c|c|c|c|c|c|c|}
\hline ADI-55689 & 0.037 & 0.013 & $>10$ & 0.30 & N.D. & N.D. & Neut. $\mathrm{IC}_{50}(\mu \mathrm{g} / \mathrm{ml})$ \\
\hline ADG-1 & 0.042 & 0.015 & $>10$ & 0.022 & N.D. & N.D. & $<0.01$ \\
\hline ADI-55688 & 0.021 & 0.012 & 1.5 & 3.2 & N.D. & N.D. & $0.01-0.1$ \\
\hline ADG-2 & 0.008 & 0.006 & 0.004 & 0.030 & 0.001 & 0.001 & $0.1-1$ \\
\hline ADI-56046 & 0.14 & 0.024 & 0.032 & 0.12 & N.D. & N.D. & $1-10$ \\
\hline ADG-3 & 0.047 & 0.023 & 0.026 & 0.057 & N.D. & N.D. & $>10$ \\
\hline S309 & 0.24 & 0.11 & 0.15 & 0.11 & N.A. & 0.008 & \\
\hline REGN10987 & $>10$ & $>10$ & $>10$ & 0.034 & 0.004 & 0.001 & \\
\hline REGN10933 & $>10$ & $>10$ & $>10$ & 0.033 & 0.001 & 0.001 & \\
\hline B6/LY-CoV16 & $>10$ & $>10$ & $>10$ & 0.29 & 0.004 & 0.013 & \\
\hline LY-CoV555 & $>10$ & $>10$ & $>10$ & 0.035 & 0.005 & 0.021 & \\
\hline
\end{tabular}

D

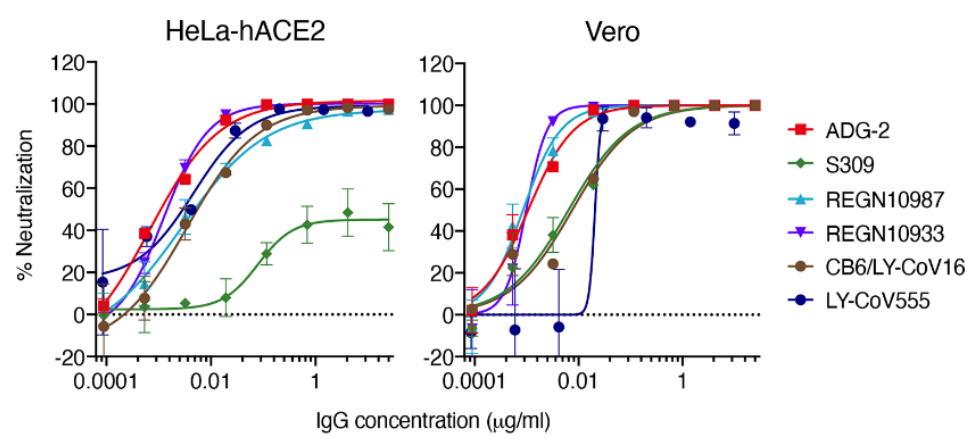

Fig. 1. Engineering SARS-CoV-2 antibodies for enhanced neutralization breadth and potency. (A) Flow cytometry plots from the terminal round of selection showing binding of parental antibodies (light blue) and affinity maturation library antibodies (dark blue) to the SARS-CoV-2 S1 protein at $1 \mathrm{nM}$. Gates indicate the yeast populations sorted for antibody sequencing and characterization. (B) Dot plots of Fab binding affinities (left) and MLV-SARS-CoV-2 pseudovirus neutralization $\mathrm{IC}_{50} \mathrm{~S}$ (right) of parental antibodies and affinity matured progeny. Clinical-stage SARS-CoV-2 antibodies are shown for comparison. (C) Heat map showing the neutralization $\mathrm{IC}_{50} \mathrm{~S}$ of the indicated antibodies against authentic SARS-CoV, WIV-1-nLuc, SHCO14-nLuc, SARSCoV-2-nLuc, and SARS-CoV-2 on either HeLa-hACE2 or Vero target cells. SARS-CoV, WIV-1-nLuc, SHCO14nLuc, and SARS-CoV-2 nLuc assays were performed on Vero target cells. (D) Authentic SARS-CoV-2 neutralization titrations performed using either HeLa-hACE2 (left) or Vero (right) target cells. The curves were fit by nonlinear regression. Error bars represent standard deviation. N.D., not determined; N.A., not applicable due to maximal neutralization plateau at $<50 \%$ neutralization; N.N., non-neutralizing. All data are representative of at least two independent experiments. 
A

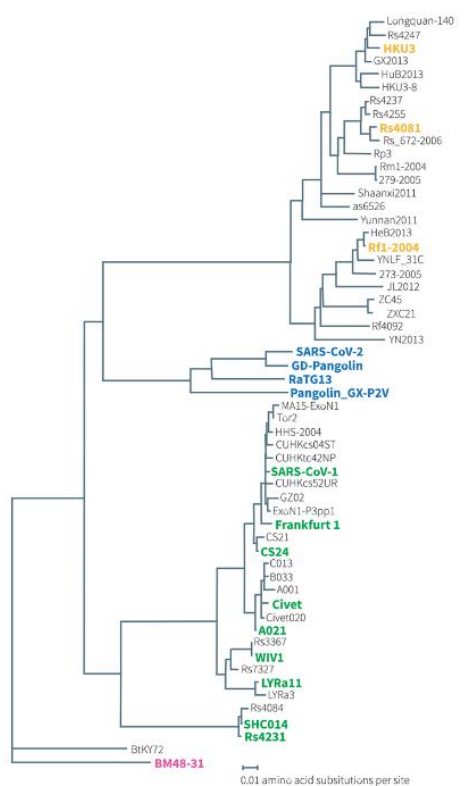

C

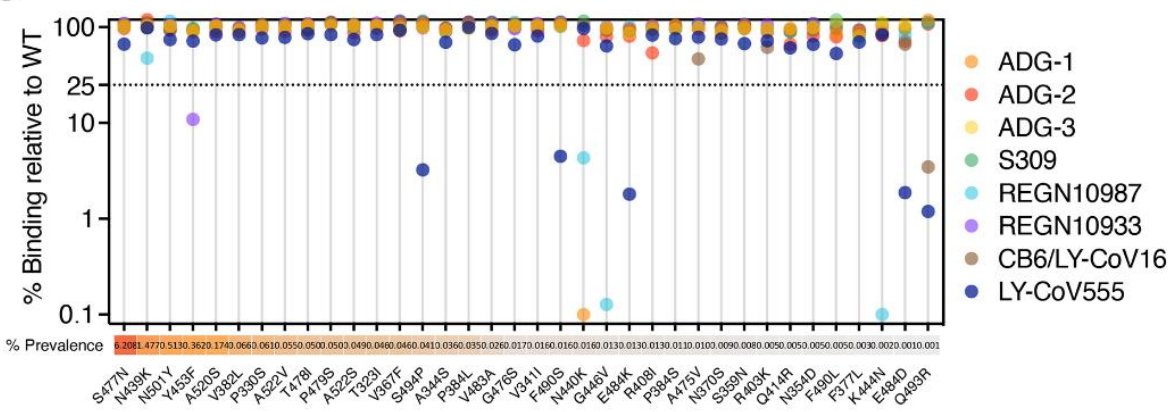

B

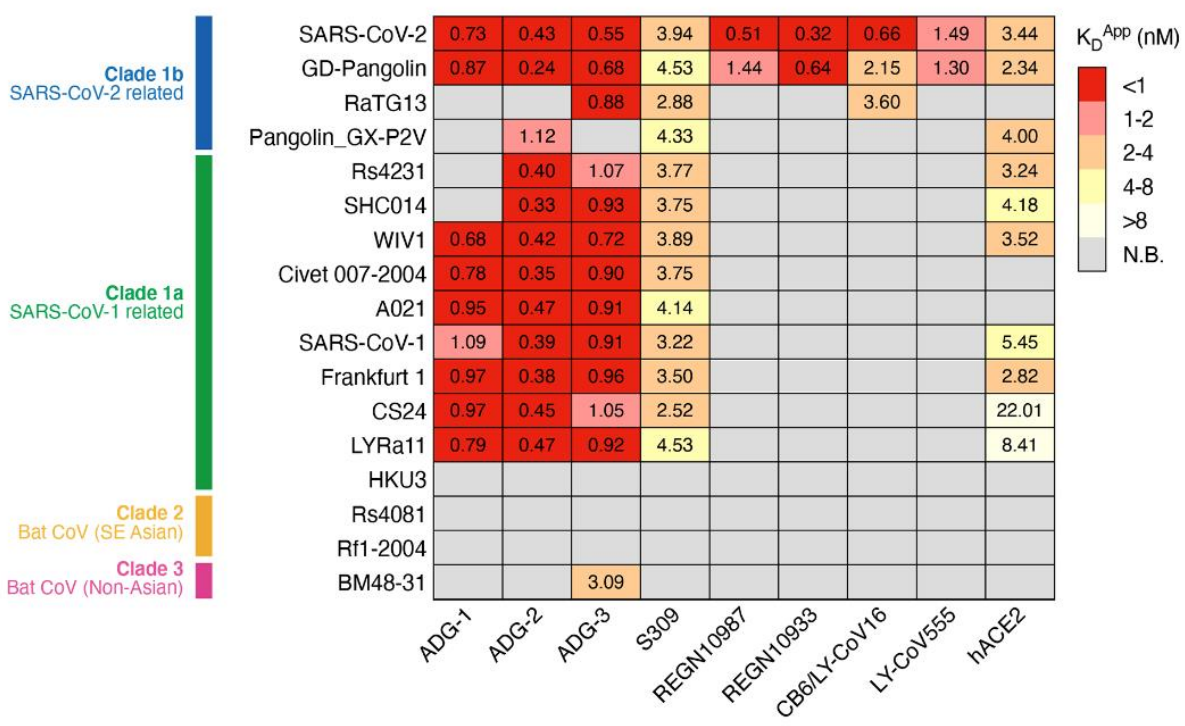

D

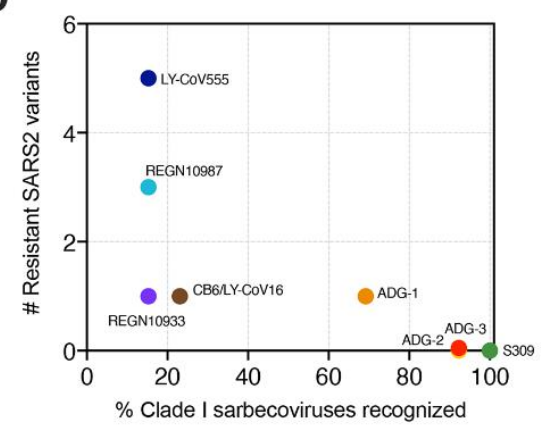

Fig. 2. Breadth of antibody binding to diverse sarbecoviruses and circulating SARS-CoV-2 variants. (A) Phylogenetic tree of 57 sarbecoviruses constructed via MAFFT and maximum likelihood analysis of RBDsubdomain 1 (SD1) amino acid sequences extracted from the European Nucleotide Archive and GISAID database. Representative sarbecovirus RBDs selected for further study are denoted in bold and colored according to their canonical phylogenetic lineages. (B) Heat map of antibody and recombinant hACE2 binding to yeast displayed RBDs from 17 representative sarbecoviruses, grouped by phylogenetic lineages. $K_{D}{ }^{A p p}$ values were calculated by normalized nonlinear regression fitting. (C) Antibody binding to naturally occurring SARSCoV-2 RBD variants displayed on the surface of yeast. SARS-CoV-2 sequences were retrieved from the GISAID database on July 14, 2020 ( $n=63,551$ ). Antibody binding signal was normalized to RBD expression and calculated as percent binding of the variant relative to the WT SARS-CoV-2 RBD, assessed at their respective $\mathrm{K}_{\mathrm{D}}{ }^{\mathrm{App}}$ concentrations for the WT construct. The prevalence of each variant, calculated from deposited GSAID sequences on December 9, $2020(n=211,539)$, is shown as a percentage of the total number of sequences analyzed. (D) Correlation between the number of resistant SARS-CoV-2 variants and percentage of clade 1 sarbecovirus RBDs recognized. N.B., non-binder under the conditions of this assay. All data are representative of two independent experiments. 
A

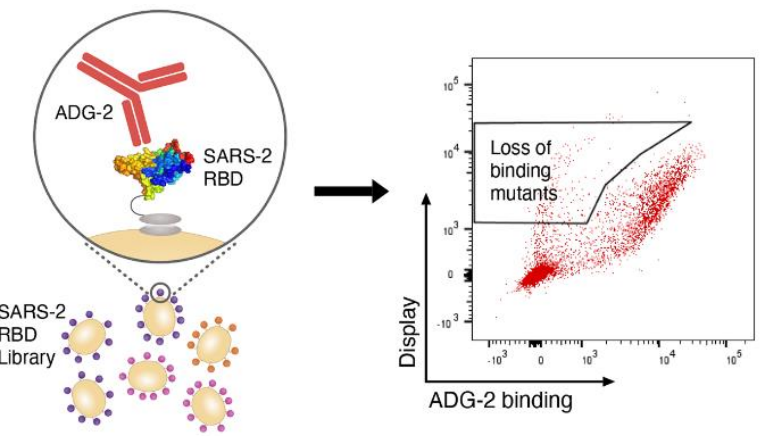

B

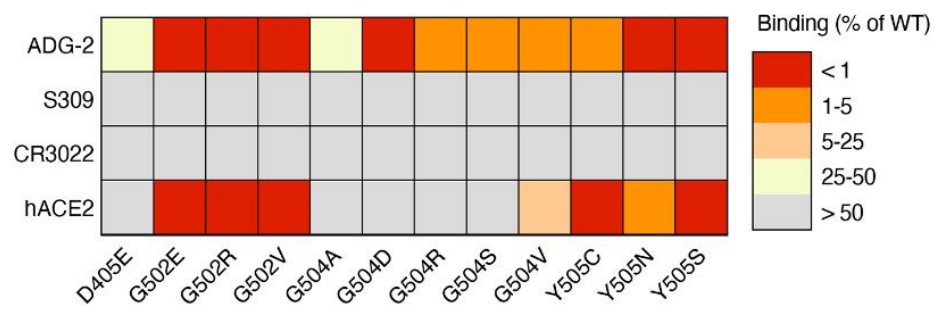

C

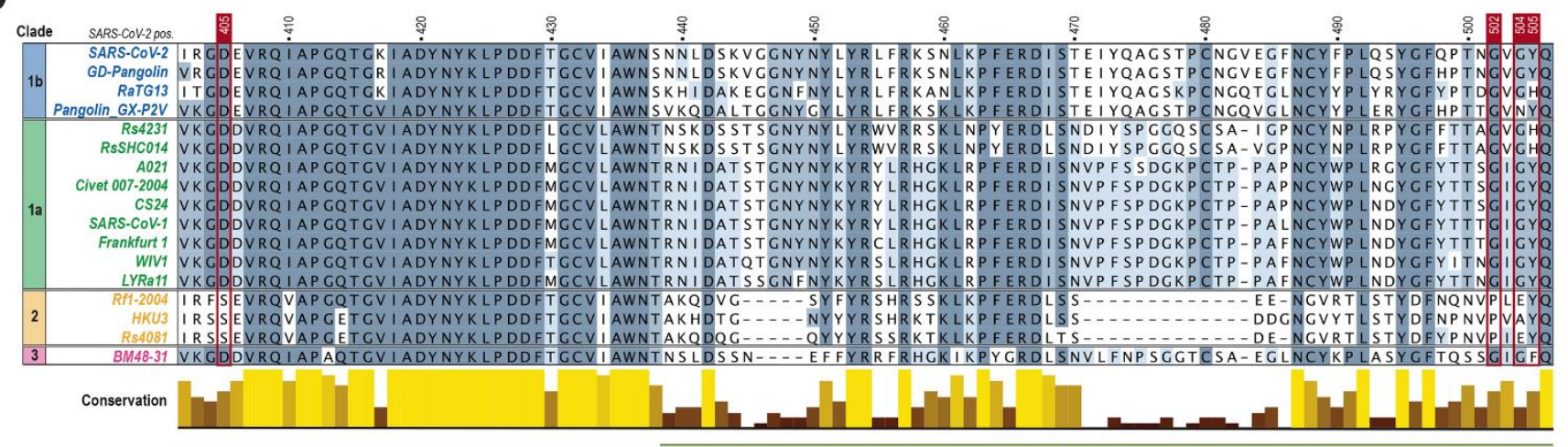

Receptor binding motif
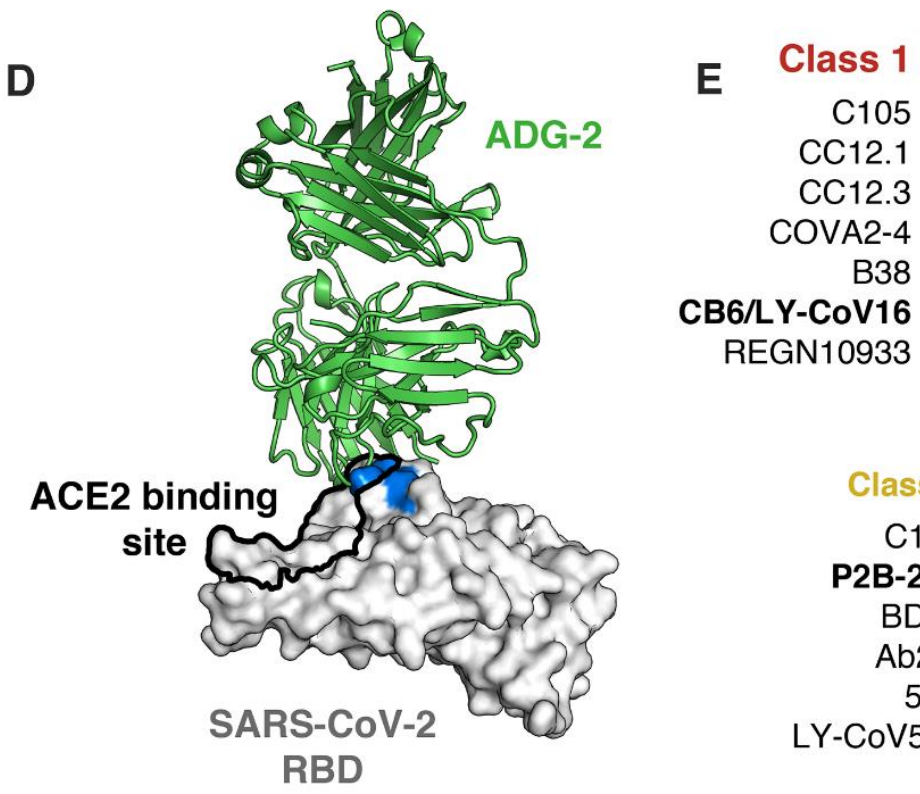

REGN10933

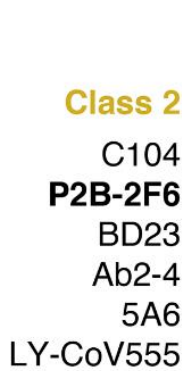

LY-CoV555

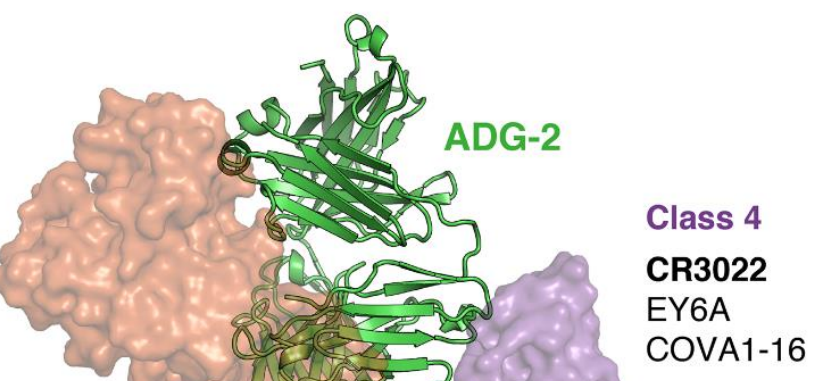

Fig. 3. ADG-2 binds to a conserved RBD epitope overlapping the hACE2 binding site. (A) Schematic showing the generation and selection of a mutagenized, yeast surface-displayed SARS-CoV-2 RBD library to identify mutations that knock-down ADG-2 binding. (B) Heat map showing mutations that abrogate binding of ADG-2 to the SARS-CoV-2 RBD. S309 and CR3022, which bind non-overlapping epitopes distinct from the ADG-2 binding site, are included to control for mutations that globally disrupt the conformation of the RBD. Values indicate percent antibody or recombinant hACE2-FC binding to the mutant SARS-CoV-2 RBD relative to the WT SARS-CoV-2 RBD, assessed at their respective $\mathrm{EC}_{80}$ concentrations for the WT RBD construct. (C) Protein sequence alignment of representative sarbecovirus RBDs with sequences colored by percentage sequence identity and conservation shown as a bar plot. Positions delineating the receptor binding motif are based on the SARS-CoV-2 RBD. Residues determined to be important for ADG-2 binding based on the data shown in (B) are denoted in red. (D) Cryo-EM reconstruction of the SARS-CoV-2 RBD bound by ADG-2, with ADG-2 knock-down mutations (blue) and the hACE2 binding site (black outline) highlighted. (E) Structures of previously reported antibodies (bold) representing frequently observed SARS-CoV-2 nAb classes 1-4 are overlaid on the ADG-2 structure (D), with additional representative SARS-CoV-2 nAbs listed. 

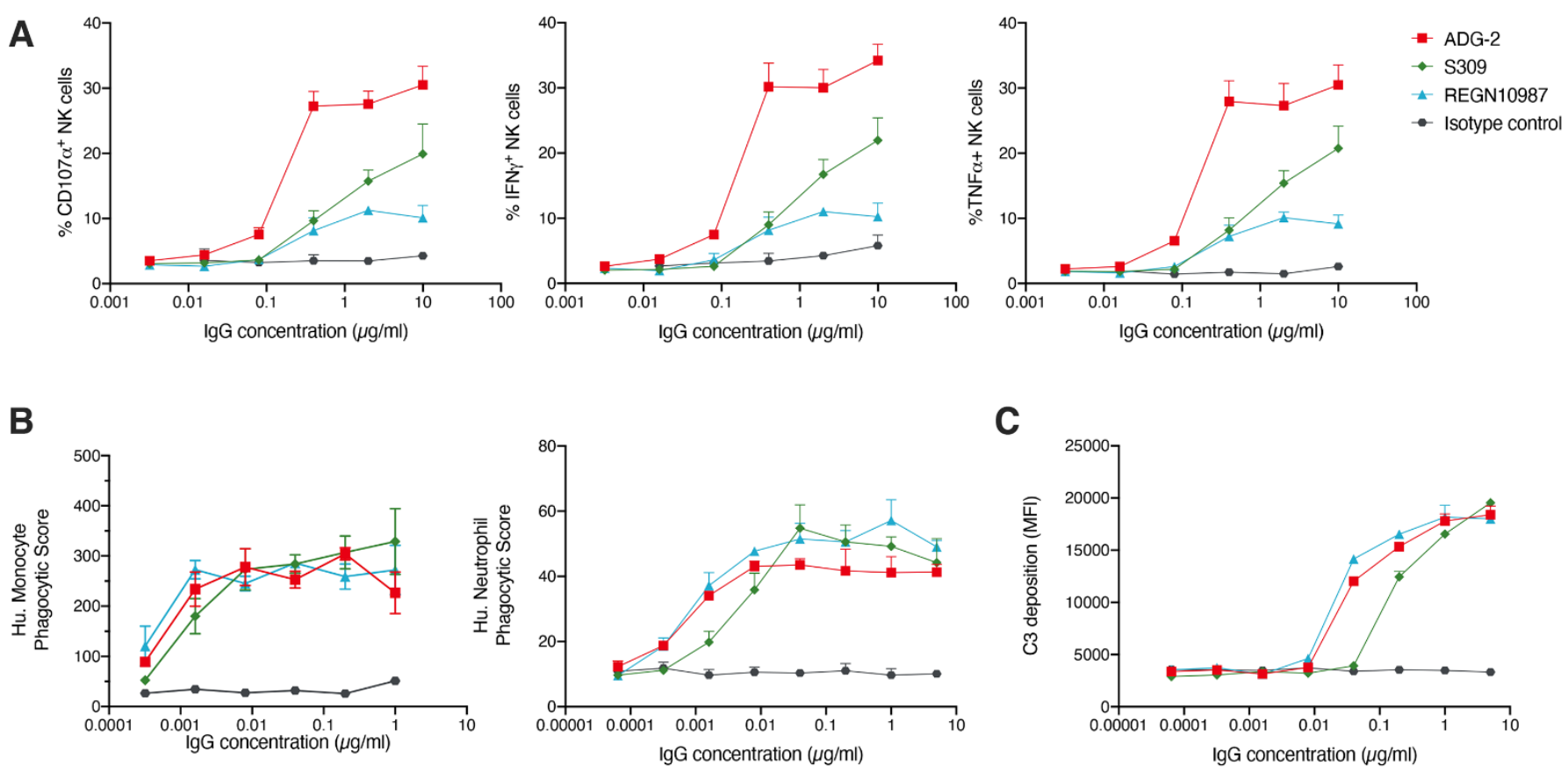

Fig. 4. ADG-2 triggers Fc-mediated effector functions. The indicated antibodies were assessed for the ability to induce Fc-mediated effector functions against RBD-coated targets at varying concentrations. (A) Primary human NK cells were analyzed for surface expression of CD107a, indicating degranulation (left), and the production of IFN $\gamma$ (middle) or TNF $\alpha$ (right) following incubation with antibody-RBD immune complexes for 5 hours. (B) Antibody-mediated phagocytosis of RBD-coated fluorescent beads by differentiated HL-60 neutrophils (left) or THP-1 monocytes (right) was measured following incubation with immune complexes for 18 hours. (C) Antibody-mediated complement deposition was measured by detection of complement component C3 onto RBD-coated fluorescent beads following incubation of guinea pig complement with immune complexes for $20 \mathrm{~min}$. All data are representative of two independent experiments. 
A

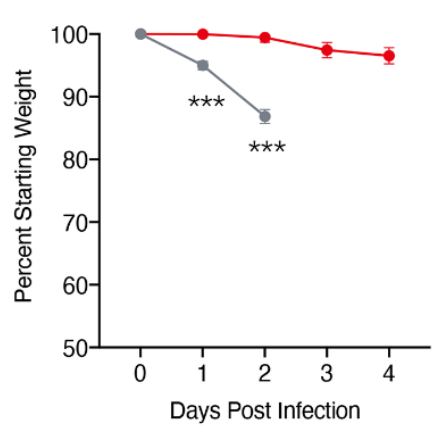

B
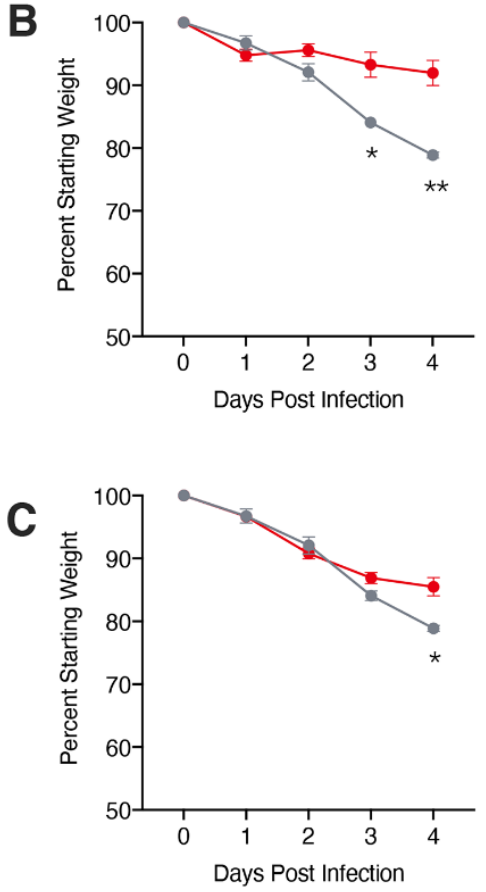

Respiratory function
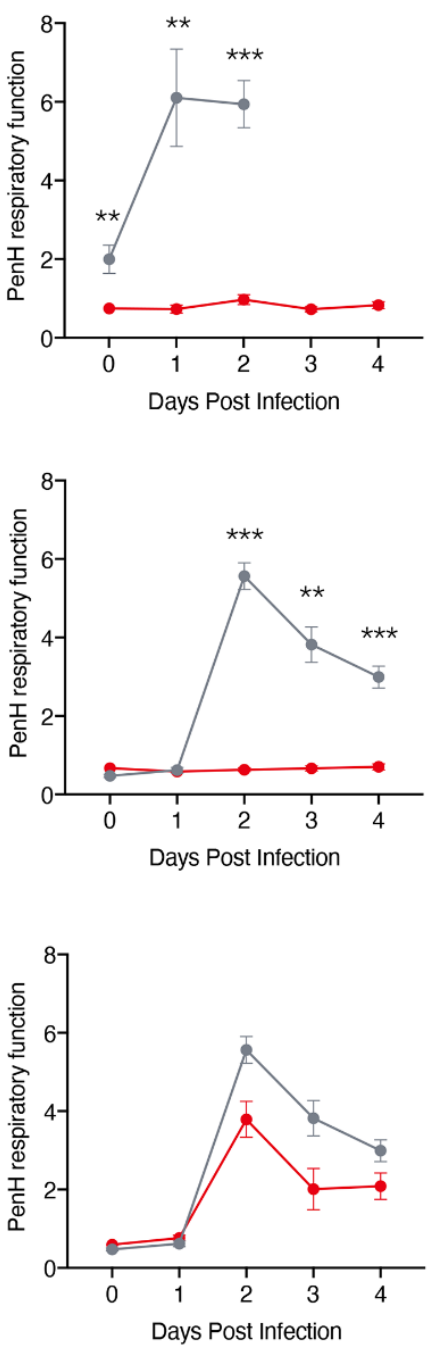

Hemorrhage Score
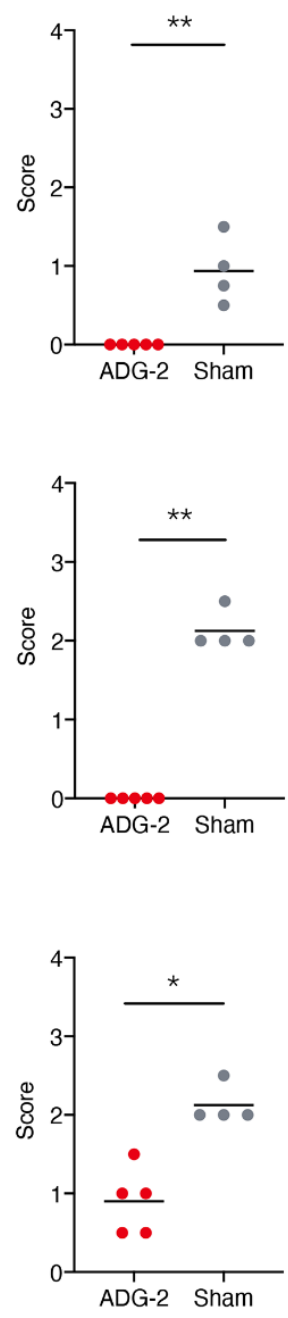

Lung viral titers
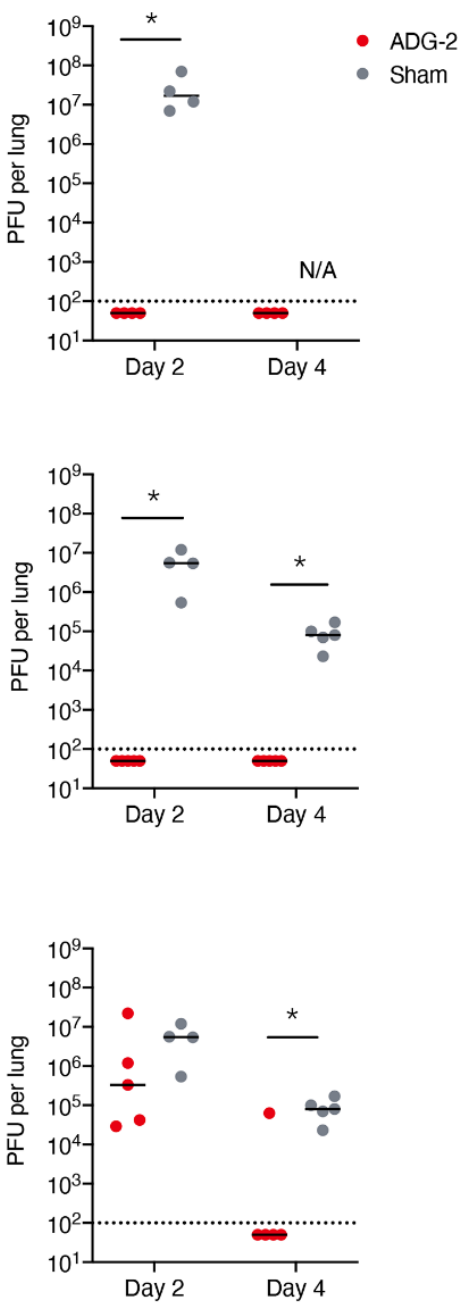

Fig. 5. Prophylactic and therapeutic administration of ADG-2 protects mice from SARS-CoV- and SARSCoV-2-associated disease. Efficacy of prophylactic treatment with ADG-2 in (A) SARS-CoV-MA15 and (B) SARS-CoV-2-MA10 challenge models. A single dose of ADG-2 or sham treatment were delivered intraperitoneally 12 hours prior to infection. Mouse body weight and respiratory function were monitored for 4 days. Gross lung hemorrhage scores were determined on day 2 (MA15) or day 4 (MA10) post-infection and lung viral titers were measured on day 2 and day 4 post-infection. (C) Therapeutic treatment with ADG-2 or sham treatment at 12 hours post-SARS-CoV-2-MA10-infection. Mouse body weight, respiratory function, gross hemorrhage scores (day 2), and lung viral titers (days 2 and 4) were assessed as described above. Statistical comparisons were made using Mann-Whitney $U$ tests or two-sided $t$ tests with Holm-Sidak corrections for multiple comparisons ( ${ }^{*} \mathrm{P}<0.05$, ${ }^{*} \mathrm{P}<0.01$; ${ }^{* *} \mathrm{P}<0.001$ ). Dotted lines indicate the limit of detection. 